\title{
BİNA KABUĞUNUN NEMSEL-ISIL PERFORMANSININ BİLGİSAYAR BENZETİMİ İLE BELİRLENMESİ
}

\author{
Ecem EDİS, Hülya KUŞ \\ İ.T.Ü. Mimarlık Fakültesi Mimarlık Bölümü 34437 Taksim / İstanbul \\ ecem@itu.edu.tr, kushu@itu.edu.tr
}

(Geliş/Received: 06.04.2012; Kabul/Accepted: 15.05.2014)

ÖZET

Bina kabuğunda neme bağlı olarak karşılaşılan yoğuşma, rutubetlenme, yüzey kaplamalarının ayrılması, kullanıcı konforunun yeterince sağlanamaması gibi sorunlar, genellikle malzemelerin mikro çevresi ve sistemin diğer bileşenleri ile ilişkisinin tasarımda tam irdelenmemiş olmasından kaynaklanmaktadır. Günümüzde, deneysel yöntemler dışında bilgisayarlı benzetimle de kabuğun kullanım sırasındaki davranışı tahmin edilebilmektedir. Binada uygun iç ortam koşullarını sağlayacak iklimlendirme sistemini ve enerji performansını belirlemeye yönelik yazılımların kullanımı artarken, bina kabuğunda nemsel-ısıl davranışı değerlendiren yazılımların kullanımı ise yeni yaygınlaşmaktadır. Yazıda, öncelikle, bina kabuğunun nemsel-1sıl davranışını analize yönelik yazılımlar genel olarak ele alınıp, yapıları ve kullanımları ile ilişkili konulara yer verilmiştir. Bu yazılımlardan WUFI 2D ile yapılan bir tip duvar tasarım çalışması açıklanarak yazılımların kullanımı örneklenmiş ve benzetimin pratikte etkin kullanımına ve yaygınlaşmasına katkıda bulunmak üzere akış diyagramları oluşturulmuştur. Sonuç olarak, bina kabuğunun nemsel-1sıl performansını değerlendiren yazılımların kullanımında 'yazılımın seçimi' ve 'yapılacak benzetimlerin planlanması' süreçlerinin benzetim ile sağlanması beklenen hedeflere erişmekte önemli olduğu belirtilmiştir.

Anahtar kelimeler: Nemsel-1sıl performans, bina kabuğu, bilgisayarlı benzetim, WUFI2D.

\section{DETERMINATION OF HYGROTHERMAL PERFORMANCE OF BUILDING ENVELOPE BY COMPUTER SIMULATION}

\begin{abstract}
Moisture-related building envelope problems such as condensation, damp, delamination of coatings, unsatisfied user's comfort requirements usually arise from the unexamined/unforeseen interactions of materials with ambient environment, and with other system components during design. Today, it is possible to estimate the inuse performance of building envelopes by computer simulations except for test methods. While use of building simulation software intended to determine indoor climate systems providing appropriate environmental conditions and to assess building energy performance is increasing, the use of simulation software to assess hygrothermal performance of building envelopes has only been recently started to spread. This paper primarily deals with computer simulation software analysing hygrothermal performance of building envelopes, and important issues associated with their structure and use are considered. A typical wall design case performed by WUFI 2D is explained for contributing to extend the efficient use of simulation software in practice. Finally, when using simulation software to assess hygrothermal performance, 'selection of appropriate software' and 'planning of simulation work' processes are found matters of utmost importance in achieving goals set by the use of simulation.
\end{abstract}

Keywords: Hygrothermal performance, building envelope, computer simulation, WUFI 2D. 


\section{GIRISS (INTRODUCTION)}

Bina kabuğunun katmanlaşması tasarlanırken kullanımdaki iklim koşulları ve kullanıcı gereksinmeleri dikkate alınmadığında, kullanıcı konforu yeterince karşılanamamakta ve bina kabuğunda rutubet, küflenme, donma-çözülmeye bağlı kopma gibi kabuğun nemsel-1sıl (hygrothermal) performansı ile ilişkili hasarlar oluşabilmektedir. Tasarımda bina ve elemanlarının performansının ve olası hizmet ömrünün tahmin edilmesi, özellikle sürdürülebilir bina açısından önemlidir (ISO 15686 [1]). Teknolojik gelişimle birlikte yapım teknikleri ve bina ürünlerindeki çeşitliliğin artması, dış ve iç iklim koşullarında projeye bağlı farklılıklar olması nedenleriyle, bina ve bina ürünlerinin kullanım performansına ve dayanıklılığına ilişkin verilerin sadece deneysel çalışmalarla elde edilmesi olanaklı değildir. Günümüzde, bu verilerin bir bölümü hesap yoluyla elde edilebilir hale gelmiştir ve benzetim yazılımları aracılığıyla da üretilebilmektedir.Yazılım kullanımındaki en önemli amaç, binanın yapıldığ bölgedeki iklim şartları altında daha uzun ömürlü, sağlıklı ve sürdürülebilir olmasını sağlamaktır.

Bilgisayarlı benzetim, bina ve bileşenlerinin kullanımdaki performanslarının tasarım sırasında tahmin edilmesi, bina ürünleri geliştirilirken olası kullanım ortamlarındaki davranışlarının analizi gibi farklı süreç, amaç ve ölçeklerde kullanılabilmekte ve buna bağlı farklı yazılımlar geliştirilmektedir. Nemsel ve 1sıl davranışı ele alan yazılımlar da, inceleme amacı ve ölçeği açısından çeşitlilik göstermektedir: EnergyPlus [2] gibi yazılımlarda odak binanın enerji performansı ve uygun iç ortam koşullarının sağlanması için kullanılacak sistemlerin değerlendirilmesi iken, WUFI [3] gibi yazılımlarda yapısal elemanlarda bütünleşik (coupled) nemsel-1sıl davranışın incelenmesi; COMIS [4] gibi yazılımlarda ise hava kalitesi gibi gereksinmeleri sağlamak için iç ortam koşullarının analizidir. Uygun nemsel-ısıl performansı gösteren bina tasarımı için, farklı amaç ve ölçekteki yazılımların birlikte kullanılması önerilmektedir [5] ve HamFitPlus gibi tüm bina analizine yönelik bütüncül yazılımlar geliştirilmeye başlanmıştır [6]. Günümüzde, enerji performansını değerlendiren yazılımlar sık kullanılırken, yapısal elemanların performansını değerlendiren yazılımların kullanımı ise o kadar yaygın değildir.

Yazıda, bu doğrultuda, yazılımların doğru ve etkin kullanımı ile yaygınlaşmasını sağlamak amacıyla önemli konular ele alınmış ve tartışılmıştır. Bu kapsamda, yapısal elemanların bütünleşik nemsel-ısıl performansını değerlendiren yazılımlar ve önemli özellikleri açıklanmış, bu yazılımlardan biri olan WUFI 2D ile yapılan bir tip duvar tasarım çalışması ayrıntılandırılarak yazılımların kullanımı örneklendirilmiştir.

\section{ELEMAN ÖLÇEĞİNDE NEMSEL-ISIL BENZETIM YAZILIMLARI (HYGROTHERMAL SIMULATION SOFTWARE AT ELEMENT SCALE)}

Nemsel-1sıl benzetim yazılımlarının yapısı, işleyişi ve kullanımı; hesaplama modeli, sayısal model ve hesaplama değişkenleri ile performans eşik değerleri açısından irdelenebilir.

\subsection{Hesaplama modeli (Computation model)}

Yazılımların hesaplama modellerinde 1s1, nem ve hava akışı tek tek veya birlikte dikkate alınabilmekte, her akış altında da farklı akış tipleri modele dahil olabilmektedir. Kullanılacak yazılım belirlenirken elemanın yeri, malzemeleri gibi özelliklerine bağlı olarak etkili olacak akışların belirlenmesi ve hesaplama modelinde bu akışları gözönüne alan yazılımların tercih edilmesi gerekmektedir. Benzetimlerde hesaplama modeline bağlı olarak tek, iki veya üç boyutlu akış ve durağan, durağandeğişken veya değişken rejimde akış modellenebilmektedir [7]. Genellikle, elemanın yapısı kaç boyutlu hesap yapılması gerektiğini tanımlamaktadır. Çok katmanlı elemanlarda bir doğrultuda malzeme farklılaşması var ise tek boyutlu hesap yeterli olabilirken, iki ya da üç doğrultuda malzeme farklılaşmasında ise buna uygun hesaplama modeli seçilmelidir.

Uluslararası ortamda 50'den fazla bütünleşik nemsel1sıl benzetim yazılımı bulunmaktadır [8]. Bunlar, hesaplama modeli, oluşturulma amacı ve inceleme ölçeğine göre farklılaşmaktadır. Genel kullanıma açık, yapı elemanı ölçeğinde bazı yazılımların bu bölüm kapsamında incelenen konulara ilişkin özellikleri Tablo 1'de verilmiştir.

\subsection{Sayısal model ve hesaplama değişkenleri (Numerical model and computational variables)}

Benzetimle analizde, öncelikle yapısal elemanın sayısal modeli oluşturulmaktadır. $\mathrm{Bu}$ kapsamda, yazılımın kendi araçları veya ek yazılımlar kullanılarak, elemanın biçim, boyut ve katmanlar gibi özelliklerini tanımlayan geometrik model ve sonlu farklar gibi ă̆ gerektiren yöntemler kullanan yazılımlarda sayısal ăg tanımlanmaktadır. Modelde kullanılabilecek biçimler (ör. dikgen, üçgen), modelin elemanın gerçekteki biçimine ne düzeyde benzerlik göstereceğini belirlemektedir. Sayısal ağdaki eleman sayısı, boyutları ve dağılımı hesaplamanın doğruluğunu etkilemektedir. Farklı sayıda, boyutta ve dağılımda elemana sahip ağlar ile hassasiyet analizi yapılarak uygun sayısal ağın seçilmesi önemlidir.

Model oluşturulurken bileşen malzemeleri ve elemanın bulunduğu ortam koşulları da tanımlanmaktadır. Malzemeler, yazılımın veritabanından seçilebilir veya istenen özgün özellik verileri ilgili arayüze girilebilir. Her yazılımda 
Tablo 1. Yapı elemanı ölçeğinde bazı nemsel-1sıl benzetim yazılımları (Some hygrothermal simulation software at building element scale)

\begin{tabular}{|c|c|c|c|c|c|c|c|c|}
\hline Yazılım & \multicolumn{2}{|c|}{$\begin{array}{c}\text { Boyut-Temel } \\
\text { akışs }\end{array}$} & $\begin{array}{l}\text { Nem akış } \\
\text { tipi }\end{array}$ & $\begin{array}{l}\text { Nem } \\
\text { tipi }\end{array}$ & $\begin{array}{c}\text { Is1 akış } \\
\text { tipi }\end{array}$ & \multicolumn{2}{|c|}{ Malzeme özellikleri } & $\begin{array}{l}\text { Diş ortam } \\
\text { bileşenleri }\end{array}$ \\
\hline 1D-HAM $[10,11,12]$ & \multicolumn{2}{|l|}{ 1B-IHN } & I, II & $\mathrm{A}, \mathrm{C}$ & i, ii, iii, iv & \multicolumn{2}{|r|}{$1,3,4,5,6,13$} & $\mathrm{a}, \mathrm{b}, \mathrm{c}, \mathrm{d}, \mathrm{h}$ \\
\hline DELPHIN $5[6,9,13]$ & \multicolumn{2}{|c|}{ 1B/2B-IHNK } & I, II, III & $\mathrm{A}, \mathrm{B}, \mathrm{C}$ & i, iii,iv & \multicolumn{2}{|c|}{$1,2,3,4,5,7,8,9,11,13$} & $\mathrm{a}, \mathrm{b}, \mathrm{c}, \mathrm{d}, \mathrm{e}, \mathrm{f}, \mathrm{g}, \mathrm{h}$ \\
\hline HygIRC-1D $[9,14,15]$ & \multicolumn{2}{|l|}{ 1B-IHN } & II, III & $\mathrm{A}, \mathrm{B}$ & i, iii, iv & \multicolumn{2}{|c|}{$1,3,4,5,6,8,9,13$} & $\mathrm{a}, \mathrm{b}, \mathrm{d}, \mathrm{e}, \mathrm{f}, \mathrm{g}, \mathrm{i}, \mathrm{j}$ \\
\hline GLASTA $[9,16]$ & \multicolumn{2}{|l|}{ 1B-IN } & II, III & $\mathrm{A}, \mathrm{B}$ & $\mathrm{i}$ & \multicolumn{2}{|c|}{$1,3,4,6,7$} & $\mathrm{a}, \mathrm{b}, \mathrm{d}, \mathrm{h}$ \\
\hline WUFI 2D [3,9] & \multicolumn{2}{|l|}{ 2B-IN } & II, III & $\mathrm{A}, \mathrm{B}$ & i, iii, iv & \multicolumn{2}{|c|}{$1,2,3,4,5,6,8,10,11,12$} & $\mathrm{a}, \mathrm{b}, \mathrm{d}, \mathrm{e}, \mathrm{f}, \mathrm{g}, \mathrm{h}, \mathrm{i}$ \\
\hline $\begin{array}{l}\text { Kısaltmalar/semboller: } \\
\text { Boyut-Temel akış- } \\
\text { Nem akış tipi- } \\
\text { Nem tipi- } \\
\text { Isı akış tipi- } \\
\text { Malzeme özellikleri- }\end{array}$ & $\begin{array}{l}\text { B: Boyut } \\
\text { I: Taşınım } \\
\text { A: Buhar } \\
\text { i: İletim } \\
\text { 1: Yoğunluk } \\
\text { 6: Buhar geçirgenlik } \\
\text { 11: Su iletkenlik } \\
\text { a: Sicaklık } \\
\text { f: Rüzgar yönü }\end{array}$ & $\begin{array}{l}\text { I: } \\
\text { II: } \\
\text { B: } \\
\text { ii: } \\
2: \\
7: \\
12 \\
\text { b: } \\
\text { g: }\end{array}$ &  & $\begin{array}{l}\text { nu } \\
\text { apasitesi } \\
\text { ler }\end{array}$ & $\begin{array}{l}\text { H: Hava } \\
\text { III: Kılcallık } \\
\text { C: Nemli hava } \\
\text { iii: Işınım (Gü } \\
\text { 3: Özgül ısıl k } \\
\text { 8: Sıvı difüzyo } \\
\text { 13: Hava geçiı } \\
\text { c: Hava basıno } \\
\text { h: Uzun dalga }\end{array}$ & $\begin{array}{l}\text { leş) } \\
\text { pasite } \\
\text { nu } \\
\text { genlik } \\
\text { leğişim }\end{array}$ & $\begin{array}{l}\text { iv: Gizli ısı } \\
\text { 4: Isı iletkenlik } \\
\text { 9: Emme } \\
\text { 14: Histeresis } \\
\text { d: Güneş ışıması } \\
\text { i: Bulutluluk } \\
\end{array}$ & $\begin{array}{l}\text { 5: Sorpsiyon } \\
\text { 10: Difüzyon direnç f. } \\
\text { e: Rüzgar hızı } \\
\text { j: Su sızıntısı }\end{array}$ \\
\hline
\end{tabular}

kullanılan özgün özellikler farklıdır. Kimi özellik verileri standart deneylerle elde edilebilir iken, kimi özellik verileri ise kapsamlı deneyler gerektirmekte ve her malzeme için kolaylıkla bulunamamaktadır. $\mathrm{Bu}$ nedenle, gerekli verilerin tipi ve veritabanındaki malzemelerin çeşitliliği yazılımın etkin kullanımını etkilemektedir. Ortam koşullarını belirleyen iklimsel veriler de her yazılımda farklılık göstermektedir. Tanımlamada, yazılımın veritabanı, yardımcı iklim yazılımları ve diğer kaynaklar kullanılabilmektedir. İklim verilerinin elle düzenlenmesi uzun zaman gerektirdiğinden, veritabanında bulunmaları veya kolay elde edilebilmeleri yazılımın etkin kullanımını sağlamaktadır. Malzeme özellikleri ve ortam koşullarına ilişkin belirsizlikler hesaplama sonuçlarını etkileyeceğinden, hassasiyet analizi için benzetimler yapılması önerilmektedir [9].

Hesaplama değişkenleri; tekrar sayısı, hesaplama zaman aralığı gibi hesaplamanın nasıl yapılacağına ilişkin değişkenlerdir ve sonuçların doğruluğu ile hesaplama süresini etkilemektedir. Küçük zaman aralığı sonuçların doğruluğunu arttırmakla birlikte, uygun iklim verisi bulunmadığında yapılan enterpolasyon hataya neden olabilmektedir [17]. Büyük yakınsama ölçütü ve az tekrar sayısı hesaplama süresini düşürürken sonuçların doğruluğunu azaltabilmektedir. Hesaplama çıktılarında, sonuçların tipi (ör. ölçme birimi) ve sunum biçimi değerlendirmeyi sınırlayabileceğinden, amaca uygunlukları önemlidir.

\subsection{Performans eşik değerleri (Performance limit values)}

Binada performans eşik değerleri; insan sağlığ1 ve konforu, mekan içindeki işlevler veya nesneler için uygun koşullar ve binanın dayanıklılığı dikkate alınarak belirlenmektedir [18]. Benzetim sonuçları değerlendirilirken, eşik değerlerine ihtiyaç duyulmakta ve bu değerler, yönetmelik, standart, bilimsel rapor, vb. dokümanlarda bulunabilmektedir.

\section{UYGULAMA ÖRNEĞİ - TIPP DUVAR TASARIMI (CASE STUDY - TYPICAL WALL DESIGN)}

Örnek olarak verilen çalışmada; malzeme, bileşen ve eleman ölçeğinde deney ve benzetim çalışmalarını içeren bir araştırma projesinden [19] yararlanılmıştır. Bina tasarımı sırasında dış duvar katmanlaşmasına karar verilirken, belirli ortam şartlarında nemsel-1sıl davranışı önceden bilinen, performans gereksinmelerine uygun seçenekleri belirlemeyi amaçlayan çalışma, İstanbul ili iklim koşulları için gerçekleştirilmiştir [20].

Duvar seçeneklerinde gövde olarak $19 \mathrm{~cm}$ kalınlığında pomza agregalı beton (PAB) blok kullanılmıştır. İstanbul'daki binaların dış duvarlarında, kolonlar ve kirişler de dahil olmak üzere, kabul edilebilir en yüksek 1s1 geçirgenlik değeri $0,60 \mathrm{~W} / \mathrm{m}^{2} \cdot \mathrm{K}$ 'dir [21]. Seçilen blok ile bu değeri elde edebilmek için 1S1 yalıtımı kullanılması gerekmektedir. Çekme veya genleştirilmiş polistren (XPS ve EPS) tercih edildiğinde, $2 \mathrm{~cm}$ kalınlığında levhalar ile bu değer sağlanabilmektedir. Uygulamada ise, taşıyıcı bileşenlerdeki ısı köprülerini engellemek için 3-4 cm kalınlığında levhalar kullanılmaktadır. Bu nedenle, tip duvarlarda da $4 \mathrm{~cm}$ kalınlığında XPS veya EPS 1Sı yalıtımı kullanılmıştır. Dış ve iç kaplama, konutlardaki yaygın kullanımı nedeniyle, sırasıyla mineral ve alçı sıva olarak belirlenmiştir (Şekil 1). Yalıtım ve sıva katmanlarının performansa etkisini analiz için, 'kaplamalı-yalıtımsız' ve 'kaplamasız-yalıtımsı' iki kontrol duvarı oluşturulmuştur. Kaplamalı-yalıtımsız duvar, mevcut eski binalarda da sık görülen bir duvar tipidir. Bu tip katmanlaşmaya karşılaştırma amaçlı olarak yalıtım eklenerek analizler yapılmıştır.

Benzetimlerde, iklimsel koşullar etkisindeki çok katmanlı elemanlarda zamana bağlı iki boyutlu bütünleşik nemsel-ısıl davranışı hesaplayan WUFI 2D kullanılmıştır. Yazılımın hesaplama modelinde; 1S1 
akıșı için 1sı iletimi, faz değişikliklerine bağlı entalpi akışları, kısa dalga güneş 1şınımı ve uzun dalga ışınım soğuması; su buharı akıșında buhar ve çözelti difüzyonu; sıv1 akıșında kılcal iletim ve yüzey difüzyonu dikkate alınmaktadır [3]. Model, deneysel ölçümlerle büyük oranda onanmıştır [7].

\subsection{Sayısal modelin kurulması (Generation of numerical model)}

Benzetimlerde kullanilan sayısal modeller 5 sira blokla oluşturulmuştur. Gövdeyi temsil eden bölümde x-/y-ekseninde 38/404 ağ elemanı bulunmaktadır. Türkiye'deki ürünler için bazı özgün özellik değerleri bilinmediğinden malzemeler tanımlanırken yazılımın veritabanı kullanılmış; Türkiye'de üretilen ürünlerin bilinen özellikleri derlenerek bunlara en yakın değerlere sahip veritabanı seçenekleri kullanılmıştır. Duvar gövdesi ve sıva yaş uygulama olduğundan tüm katmanların başlangıç bağıl nemi \%80, sıcaklığg $20 \mathrm{C}^{\circ}$ olarak tanımlanmıştır. Dış yüzeyde, karşılaştırma için, rüzgarla itilen yağmur (RIY) yükü yüksek, güneşlenme miktarı düşük olan, şiddetli koşullara sahip kuzeybatı (KB) ve görece ortalama koşullara sahip güneydoğu (GD) yönleri için benzetimler yapılmıştır (Şekil 2a). İç yüzeyde, EN 15026 standardına göre normal kullanım için İstanbul ili iklimine göre yazılım tarafindan oluşturulan veriler kullanılmıştır (Şekil 2b). Duvarın alt ve üst yüzeyleri 1S1 geçirmez olarak seçilmiştir. Model kurma süreci, modelde kullanılan diğer değişkenler ve yazılım olanakları ile ihtiyaç duyulan veriler Tablo 2'de verilmiștir.

Duvar seçeneklerini değerlendirmeye yönelik benzetimlerden önce, sayısal modeli denetlemek üzere kontrol benzetimleri ile elemandaki blok sira sayıs1, ağ elemanı sayısı, RIY katsayısı ve yağmur suyu emme çarpanının uygunluğu irdelenmiştir.

Eleman ölçeğinde benzetimde, elemanın gerçekteki boyut ve biçimine benzer şekilde modellenmesi, gerçek koşullarla benzeşim için önem taşımakla birlikte, ağ elemanı sayısı ve hesaplama süresi arttığı için sonuçların doğruluğu dikkate alınarak ortalama bir çözüme gidilmesi gerekmektedir. Örneğin, RIY yükü üzerine bir çalışmada, detaylandırılmamış geometrik model ile, ölçümle belirlenen değerlerden farklı RIY yükü hesaplanabildiği bildirilmektedir [22]. Bu doğrultuda, blok sıra sayısını belirlemek için; 5 ve 10 sira blokla oluşturulan KD-2 duvarı KB yönünde yüksek yağmur etkisi ile çalışılmıştır. 3 . sıradaki bloklar karşılaştırıldığında, gözlenen en yüksek bağıl nem ve sicaklık farkları çok düşük olduğu için benzetimlerde 5 siralı model kullanılmıştır.

Uygun ağ elemanı sayısı belirlenirken, eleman sayısı iki katına çıkartıldığında sonuçların değişmemesi veya benzer değerler elde edilmesi gösterge olabilmektedir. Bu kapsamda; 5 siralı KD-2 duvarı KB yönü için, x/y-ekseninde 28/304 ve 38/404
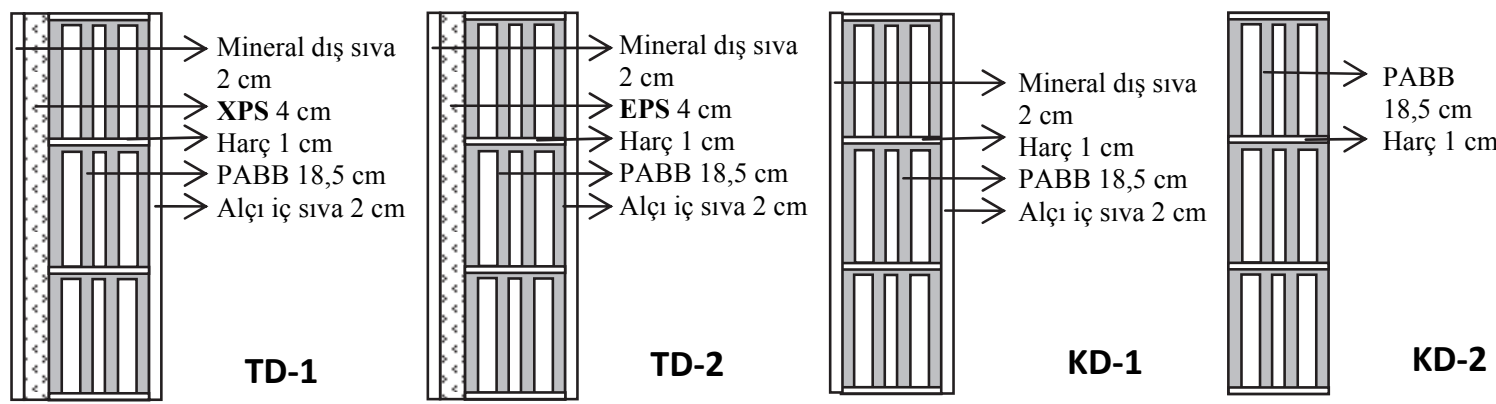

Şekil 1. Tip duvar ve kontrol duvarı seçenekleri (Typical and control wall alternatives)
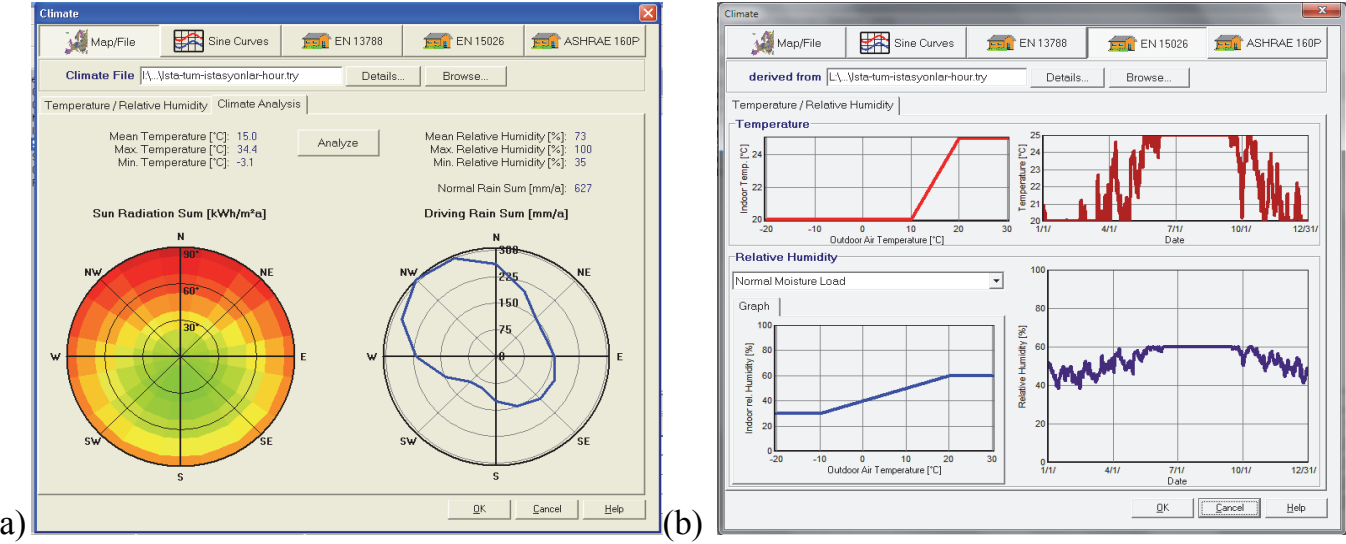

Şekil 2. İklim verileri: (a) güneş radyasyonu, $k W h / m^{2} \cdot y l l$ ve RIY, $m m / y l l$ yükü; (b) iç ortam sıcaklığı, $C^{o}$ ve bağıl nem, $\%$ (Weather data: (a) solar radiation, $k \mathrm{Wh} / \mathrm{m}^{2} \cdot a$ and wind-driven rain, $\mathrm{mm} / \mathrm{a}$ load (b) interior temperature, ${ }^{\circ} \mathrm{C}$ and relative humidity, $\%$ ) 
Tablo 2.Yazılımın olanakları/ihtiyaç duyulan veriler ve modellerde kullanılan değerler (Capabilities and required inputs of software, and values used in the models)

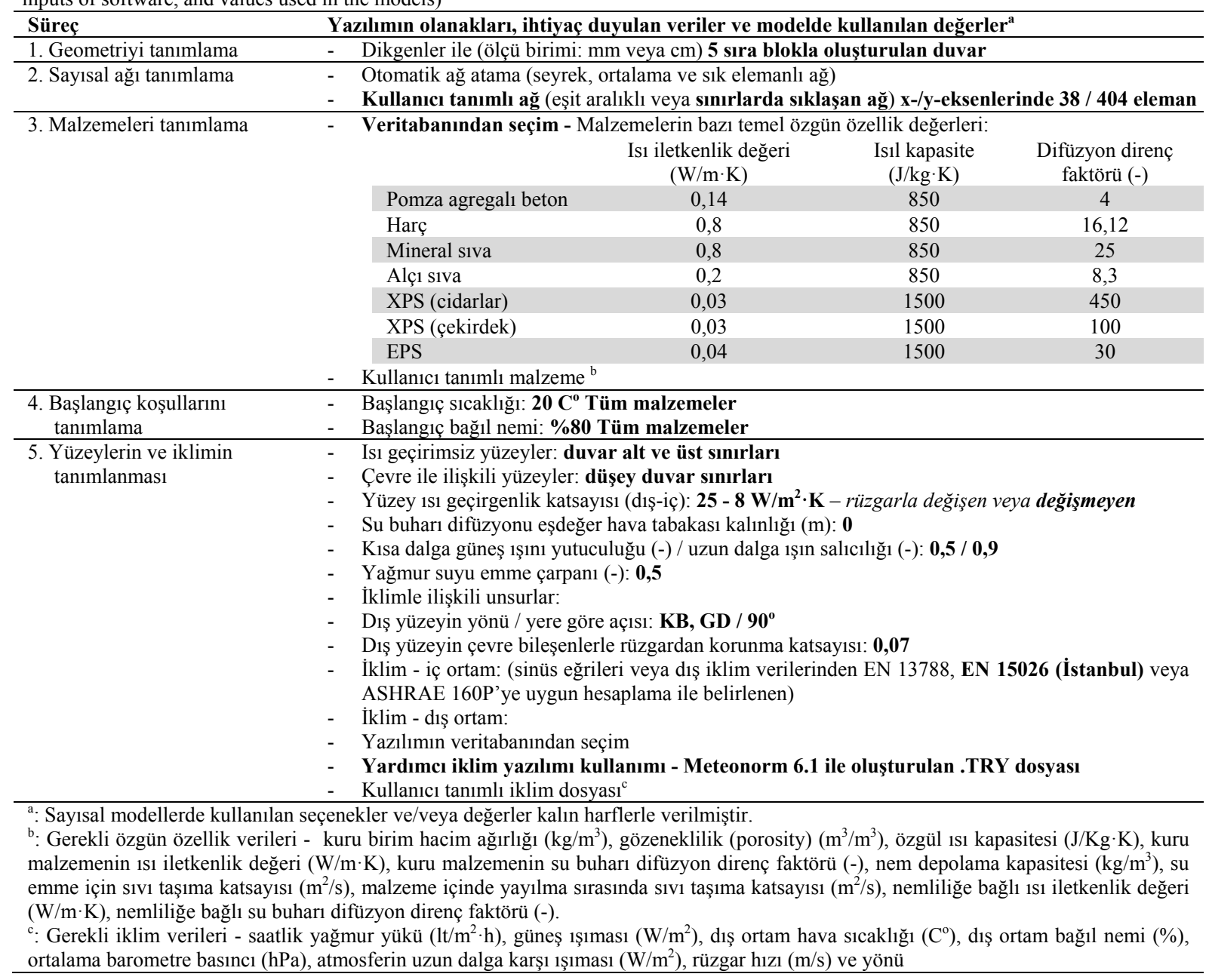

eleman bulunan ağlar için çalışılmıştır. Y-eksenindeki eleman sayısı fazla olduğu için her iki yönde de yalnızca \%25 arttırım yapılmıştır. Sonuçlar arasında önemsiz farklılıklar olmakla birlikte, y-eksenindeki eleman sayısı çok fazla olduğu için, benzetimlerde yeni arttırım yapılmadan x-/y-ekseninde 38/404 eleman bulunan ăg kullanılmıştır.

Yağmur suyu emiciliği ve RIY yükünü belirleyen değişkenler de, sonuçları etkileyebilmektedir. WUFI 1D ile yapılan bir çalışmada, yağmur suyu emme çarpanı 0,03 'den 0,1 'e çıkarıldığında dış sıvanın bağı neminin yaklaşık \%20 oranında değiştiği bildirilmiştir [23]. Bu çalışmada, RIY etkisini tanımlayan katsayılar için; 5 sıralı TD-1 duvarı KB yönünde üç durum için çalışılmıştır: (i) yağmur suyunun sıçrayıp uzaklaştığı durum - yağmur etkisi yok, (ii) çevre binalarla korunan duvarda, yüzeye gelen yağmur suyunun \%50'sinin yüzeyde kaldığı durum - ortalama yă̆mur etkisi, ve (iii) binalarla korunmayan duvarda, yağmur suyunun \%50'sinin yüzeyde kaldığı durum yüksek yağmur etkisi. Karş1laştırmada, 3. sıradaki blok katmanlarında ve katman sınırlarındaki ağ elemanlarında görülen ortalama sıcaklık ve bağıl nem değerleri kullanılmıştır. Bağıl nem açısından, artan yağmur yükü ile birlikte yalnızca dış sıva katmanında farklılık oluştuğu, pomza katmanlarında ise önemli farklılıklar oluşmadığ 1 görülmüş ve tip duvar tasarımı için hesaplamalar ortalama yağmur etkisine göre yapılmıştır.

\subsection{Hesaplama (Computation)}

Benzetim başlangıç tarihi, yapım suyunun kuruması sırasındaki davranışı da gözlemek üzere, dış duvarların çoğunlukla inşa edildiği yaz dönemi temel alınarak 1 Haziran olarak belirlenmiş ve bir yıllık benzetimler yapılmıştır. Ayrıca, çeşitli durum ve tip duvarlar için üç yıllık benzetim yapılarak katmanların davranışındaki değişim kontrol edilmiş ve yıllık olarak tekrar eden bir davranış olduğu gözlenmiştir (Şekil 3).

\subsection{Sonuçların değerlendirilmesi (Assessment of results)}

Sonuçlar, benzetim süresince elemandaki davranışı gösteren $2 \mathrm{~B}$ videolar veya istenen bölgelerin benzetim süresince davranışını gösteren 1B grafikler ile verilmektedir. Analizlerde, videoda istenmeyen davranış görülen bölge için 1B grafik 


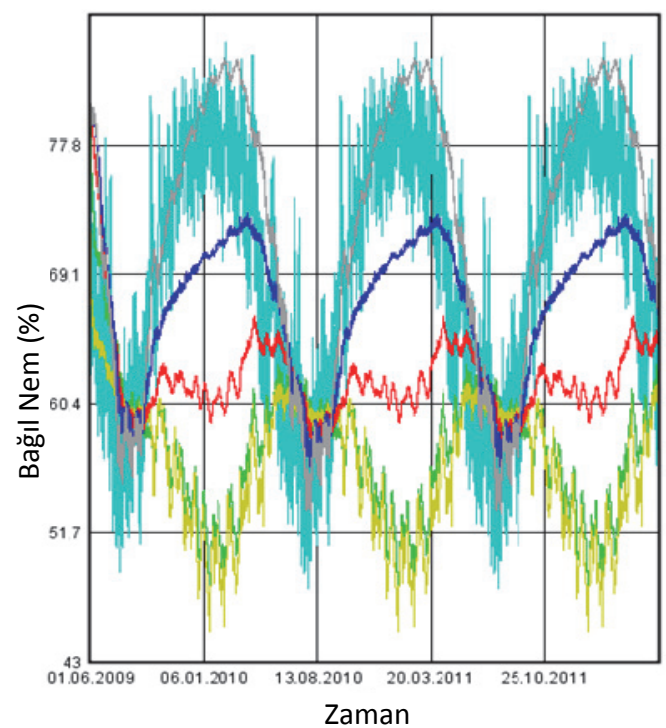

(a)

Şekil 3. KD-1 duvarı için üç yıllık (a) bağıl nem ve temperature results of KD-1 wall)

hazırlanabileceği gibi, amaca göre önceden seçilmiş bölgeler için doğrudan $1 \mathrm{~B}$ grafikler oluşturulabilir. $\mathrm{Bu}$ çalışma farklı durumları karşılaştırmayı amaçladığından ikinci yaklaşım kullanılmıştır.

Performans eşik değerlerine ilişkin veri bulunmadığında, genellikle, Abuku vd.lerinin [24] veya Koci vd.lerinin [25] çalışmalarında olduğu gibi, yoğuşma ve küf oluşma riski, nemin yıllar içinde artıp artmadığ1 gibi hasara neden olabilecek koşulların varlığını inceleyen, karşılaştırmalı değerlendirmeler yapılmaktadır. $\mathrm{Bu}$ çalışmada da, eşik değerlerine ilişkin yeterli veri yazında olmadığı için bu yaklaşım izlenmiştir.

Değerlendirme için, 1sı geçirimsiz sınırların etkisini önlemek üzere, 3. sıradaki katmanların ortalama bağıl nem ve sıcaklıkları kullanılmıştır. Değerlendirmede; (i) yapım suyunun kuruma süresi ve kuruma sırasındaki davranış, (ii) kuruma sonrasında duvarda nem birikimi riski, (iii) farklı 1sı yalıtım malzemelerinin davranışa etkisi ve (iv) yönlenmenin etkisi analiz edilmiş ve önemli bulunan sonuçlar aşağıda tartışılmıştır.

Yapım suyunun kuruma süresi: Is1 yalıtımlı TD-1 ve TD-2 duvarlarında kuruma, KB yönünde yaklaşık 1315 hafta sürmektedir. $\mathrm{Bu}$ süre sonunda tüm katmanların bağıl nemi yaklaşık \%60-65'dir. Sıvalı fakat 1s1 yalıtımsız KD-1 duvarında ise, katmanların bağıl nemi, ısı yalıtımlı tiplere göre 3-5 hafta daha önce aynı düzeye gelmektedir. Torres ve de Freitas [26] da, zeminden yükselen nemi azaltan bir tekniği inceledikleri çalışmada, kireçtaşı ile oluşturulan deney duvarında başlangıçtaki bağıl nemin \%65 olduğunu belirtmişlerdir. Sıvasız ve 1sı yalıtımsız KD-2 duvarında ise, kuruma yaklaşık 3 hafta sürmekle beraber, yağmur yağdığında bağıl nem \%95-100'e kadar çıkabilmektedir. Koci vd.leri [25] gazbeton ile

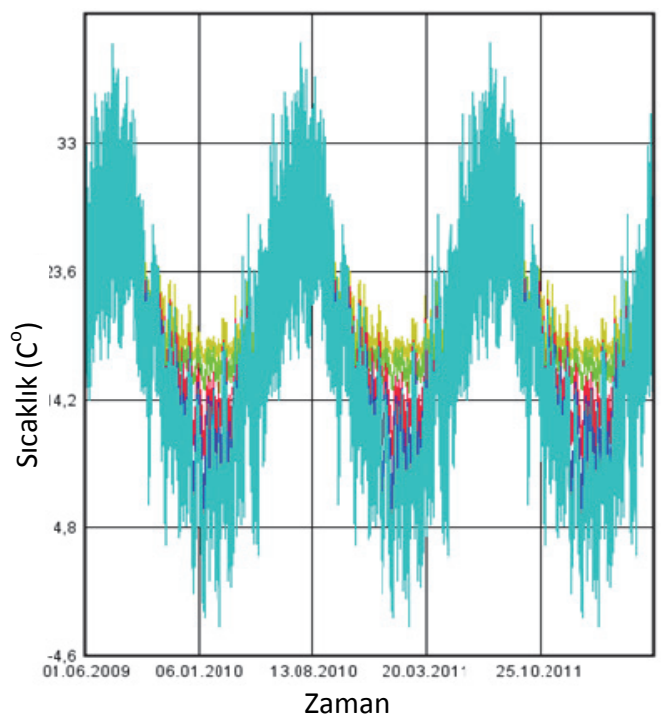

(b)

(b) sıcaklık sonuçları (Three-year (a) relative humidity and (b)

yaptıkları çalışmada eşik değeri olarak en fazla higroskopik nem miktarına karşılık gelen \%97,6 bağıl nemi kullanmışlardır. Bu açıdan bakıldığında, KD-2 duvarında kuruma hızlı gerçekleşmekle birlikte, yağmur yağdığında bağıl nem \%95-100'e çıtığı için, yalıtım ve/veya kaplamanın yağmur riski oluşmadan yapılması bloklarda nem artışını önleyecektir. Ancak, malzemeler için seçilen başlangıç koşulu değerleri hesaplanan kuruma süresini etkilediğinden gerçek kuruma süresi farklılaşabilir. Bu değerler farklı duvar tiplerinde bağıl davranışı öngörmek için referans alınabilir.

Yapım suyunun kuruması sonrasındaki davranış: TD-1 ve TD-2 duvarlarının katmanlarında kuruma sonrası nem birikimi gözlenmemiştir. Katmanların bağıl nemi, iç ve diş ortam bağıl nemindeki değişime benzer yapıda bir değişim göstermekte ve KB yönünde en fazla \%80-85'e çıkmaktadır. Dış sıva ve yalıtım katmanlarındaki bağıl nem, tüm yıl boyunca yalnızca kısa süreler için dış ortam ortalama bağıl neminden fazladır. Steeman vd.lerinin yüzeyi boyalı ve boyasız alçı plakalar üzerinde yaptıkları deneysel çalışmada [27], yüzeye etkiyen havanın bağıl nemi değiştikçe numune bağıl neminin de ilişkili bir biçimde değiştiği ve boya özelliğine bağlı olarak farklılaştığı görülmektedir. TD-1 ve TD-2 duvar katmanlarında ortam bağıl nemine ve katman yerine bağlı değişim, bu doğrultuda, anlamlı bulunmuştur. KD-1 duvarında ise, dış PAB katmanının bağıl nemi, bazı dönemlerde dış sıvadan yüksek olmakla birlikte \%85'i aşmamaktadır. Yapılan üç yıllık benzetimde, nemin yillar içinde birikmediği görülmüştür (Şekil 3).

Farklı ısı yalıtım malzemelerinin davranışa etkisi: Buhar difüzyon direnci görece yüksek XPS kullanılan TD-1 duvarı ile EPS kullanılan TD-2 duvarı karşılaştırıldığında; KB yönünde, yılın büyük bir 
bölümü için, TD-1 duvarının dış sıva ve yalıtım katmanlarında bağıl nem daha düşük, $\mathrm{PAB}$ ve iç sıva katmanlarında ise daha yüksektir. TD-1 duvarında, dış kaplamaların geçirimsizliğine bağlı olarak duvar gövdesinin yeterince kuruyamadığı, daha geçirgen dış kaplamaları olan TD-2 duvarında ise duvar gövdesinin kurumasına bağlı olarak dış kaplamanın daha nemli olduğu anlaşılmaktadır. Bağıl nem düzeyleri eşik değerlerin üzerine çıkmadığı için, oluşan fark ihmal edilebilir.

Yönlenmenin davranışa etkisi: Yöne bağlı olarak farklı şiddette iklim bileşenlerine maruz kalan TD-1 ve TD-2 duvarlarında bağıl nemdeki en büyük değişim dış sıva ve isı yalıtımı katmanlarında görülmektedir. Şiddetli koşulları olan KB yönünde bu katmanlar için hesaplanan değerler, ortalama koşulları olan GD yönü için hesaplanan değerlerden 0-16 birim daha yüksektir. PAB blok ile iç sıva ise pek fazla etkilenmemektedir. Abuku vd.leri [24], Essen için farklı RIY koşullarında küf oluşumu riskini değerlendirdikleri çalışmada, RIY yükünün en yüksek, güneş radyasyonu kazancının ortalama düzeyde olduğu batı ve RIY yükünün ortalama, güneş radyasyonu kazancının en düşük olduğu kuzey yönlerinde, yılın belirli dönemlerinde duvarın orta bölgesindeki nem miktarının daha yüksek olduğunu göstermekte ve açıklamalarında güneş radyasyonu kazancına bağlı kuruma etkisini belirtmektedirler. $\mathrm{Bu}$ çalışmada da, RIY yükünün yüksek, güneş radyasyonu kazancının düşük olduğu KB yönünde bağıl nem daha yüksek bulunmuştur.

Tüm değerlendirmelere bağlı olarak, benzetim sonuçlarının referans olarak kullanılabileceği ve 19 $\mathrm{cm}$ kalınlığında PAB bloklar ve dıştan $4 \mathrm{~cm}$ kalınlığında XPS veya EPS 1sı yalıtımı ile oluşturulan tip duvarların İstanbul ili iklim şartları için nemsel-1sıl performans açısından uygun olduğu belirlenmiştir. Ayrıca, Türkiye'deki diştan 1sı yalıtımı uygulamalarında dış sıvanın $\sim 0,5 \mathrm{~cm}$ kalınlığında kullanıldığ 1 dikkate alınarak yapılan hesaplamalarda katmanlarda nem birikimi olmadığı, sonuçlardaki değişimin performansa etkisinin ise ihmal edilebilir düzeyde olacağı görülmüştür.

\section{TARTIŞMA (DISCUSSION)}

Yapılan çalışmalar [16, 22, 28, 29, 30] benzetimle değerlendirmede; malzeme özgün özellik değerleri, iklim verileri, geometrik model gibi girdilerin doğruluğu ile incelenen nesnede etkili olması beklenen akışların/fiziksel olayların hesaplama modelinde dikkate alınıp alınmamasının sonuçların doğruluğunu etkilediğini göstermektedir. Girdiler ve hesaplama modeli büyük oranda doğru/uygun olsa dahi, hesaplama ve deney sonuçları arasında farklılıklar oluşabilmektedir. Her bileşen/katmanlaşma ve olası her farklı ortam koşulu için deney yapılması verimli bir yaklaşım olmayacağından, hesaplama sonuçlarında deney sonuçlarına göre sapmalar olabileceği göz ardı edilmeden, tasarım öncesinde ve sırasında benzetimlerden yararlanılması, istenen performansı gösteren bir bina ve yapı elemanlarını elde etmek için önemli bir katkı sağlayacaktır.

Verilen uygulama örneğinin hazırlık ve gerçekleştirme aşamalarında, amaca uygun yazılımın belirlenmesi ve etkin kullanımı için; (i) hesaplama modelinde incelenen elemanda etkili olması beklenen fiziksel akışların, gerekli veya istenen rejimde ve boyutta dikkate alınması; (ii) incelenen elemanı oluşturan malzemeler için hesaplamada gerekli özgün özellik verilerine yazılımın veritabanı, dış kaynaklar veya deney çalışmaları aracılığıyla erişilebilirliği ve (iii) ortam koşullarını tanımlamak üzere gerekli içerikte ve tipte iklimsel verilere yazılımın veritabanı, yardımcı yazılımlar veya dış kaynaklar aracılığıyla erişilebilirliği temel önemde yazılım özellikleri olarak belirlenmiştir. Sunum biçimi gibi sonuçların yapısına ilişkin unsurlar ve yazılımın geometrik modelleme araçları ve özellikleri de yazılımın etkin kullanımında önemlidir. Bu kapsamda, uygun ve etkin olarak kullanılabilecek yazılımın seçimi için ardışık olması gerekmeyen bir akış diyagramı (Şekil 4) oluşturulmuştur. Yazılım seçiminde, ayrıca, yazılımın ticari ya da serbest olması, hesaplama modelinin onanma düzeyi gibi diğer özellikler de planlanan çalışmanın hedef ve sınırlarına bağlı olarak ölçüt olabilir.

Yazılımın kullanımı sırasında; (i) inceleme amacına ve değerlendirme için gerekli performans eşik değerlerinin varlığına bağlı olarak, benzetim süresi, ortam koşulları, eleman modeli vb. açısından gerçekleştirilecek benzetimlerin önceden doğru planlanmasının ve (ii) gerçek benzetimlerden önce, eleman modelini değerlendirmek üzere sonuçların doğruluğa yakınlığı ve uygun hesaplama süreleri açısından hassasiyet analizine yönelik ön benzetimlerin yapılmasının sonuçların etkin kullanımı ve ilgili paydaşların yararlanabilmesi açısından önem taşıdığı görülmüştür. $\mathrm{Bu}$ doğrultuda, benzetimle değerlendirmenin genel aşamalarını ve önemli girdiler ile çıktıları gösteren bir akış şeması oluşturulmuştur (Şekil 5).

\section{SONUÇ (CONCLUSION)}

Binaların kullanım döneminde, yapısal elemanlarda görülen hasarların ve düşük performans problemlerinin genellikle 'davranışı bilinen ve tanınan malzemelerin sistemin diğer bileşenleri ve bulunduğu çevre ile beklenmedik etkileşimleri' sonucu ortaya çıktığ1 yaygın olarak kabul görmektedir. Nemsel-1sıl etkileşim ve buna bağlı oluşan sorunlar, özellikle bina kabuğunda sıklıkla görülmektedir. Olası hasarların ve performans sorunlarının önceden tahmin edilerek gerekli önlemlerin alınabilmesi için bina tasarımı öncesinde veya sirasinda yapılan deneysel ve 


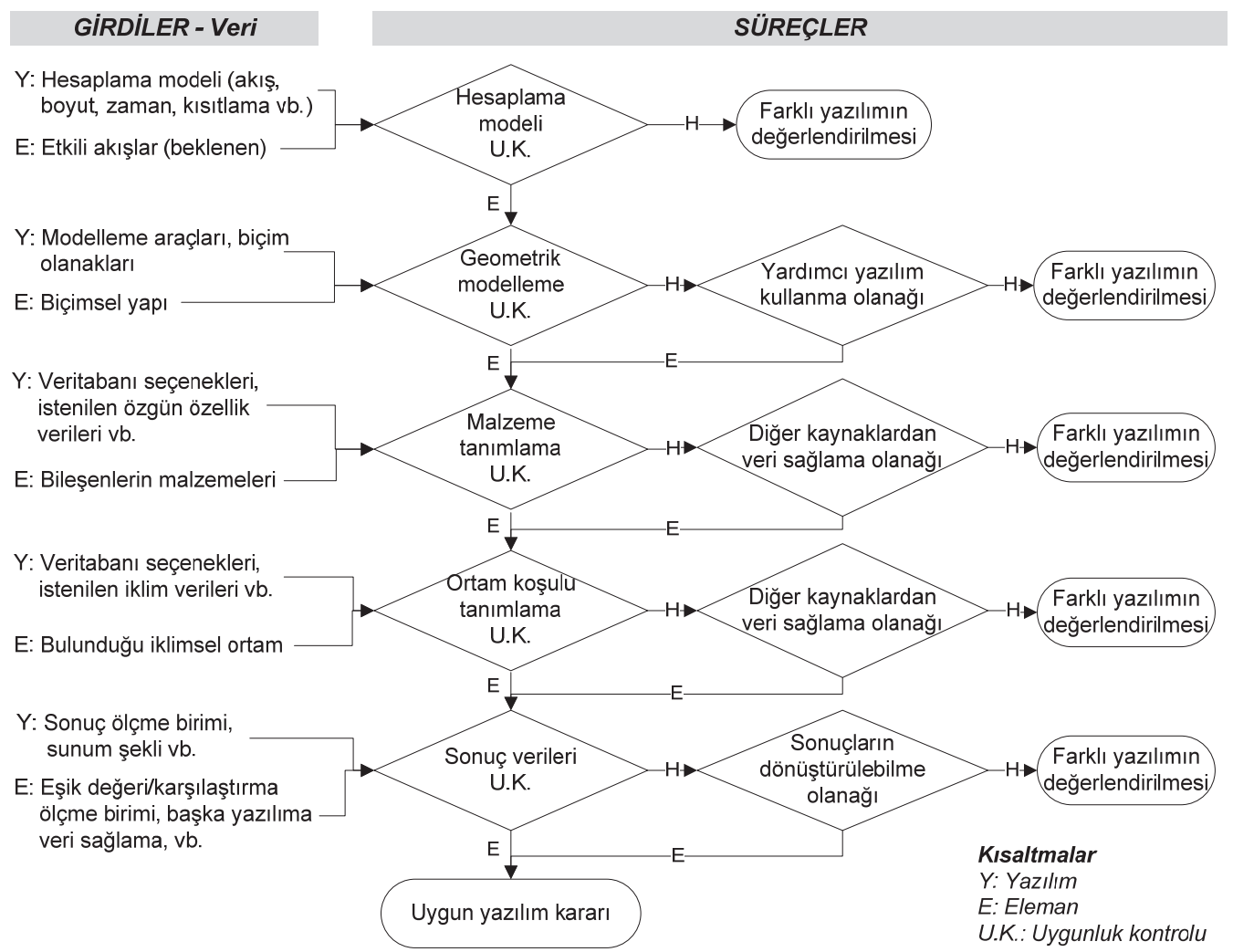

Şekil 4. Yazılım seçimi (Software selection)

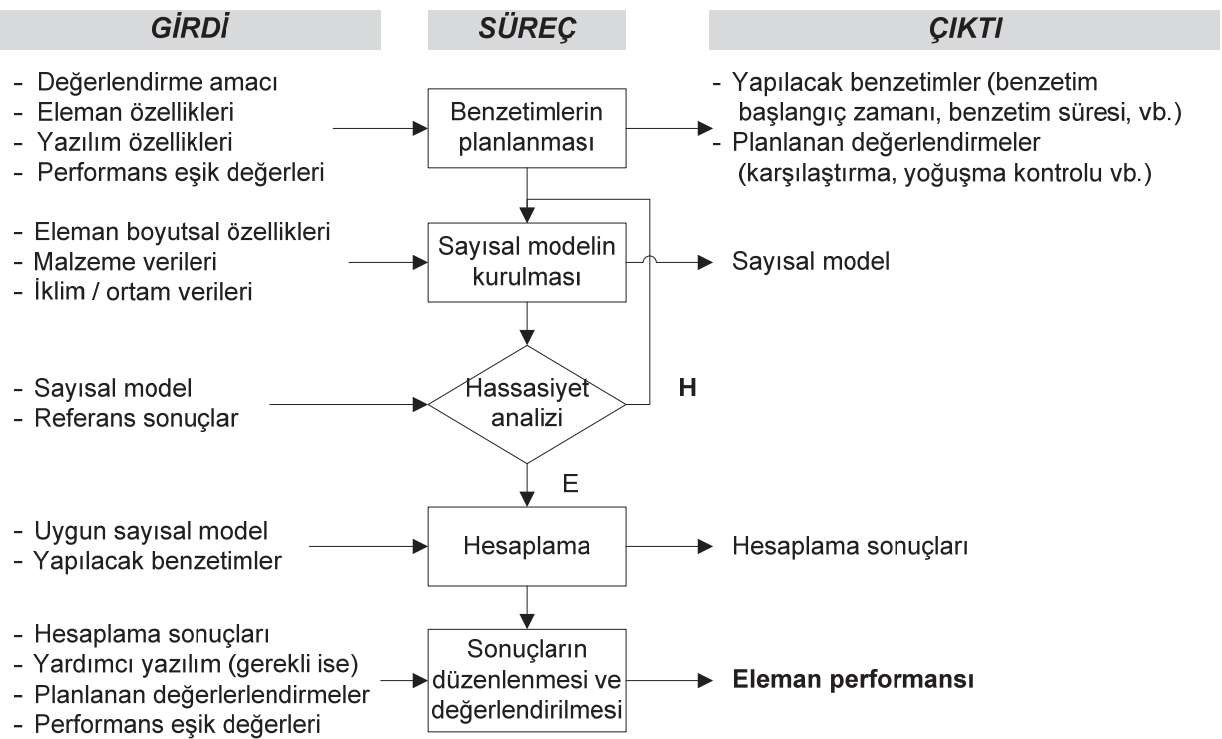

Şekil 5. Benzetim ile değerlendirme süreçleri (Processes of assessment by simulation)

bilgisayarlı benzetim çalışmalarının, ekonomik ve çevresel açıdan 'dayanıklı ve sürdürülebilir binaların elde edilmesine’ katkısı göz önüne alındığında, önemi giderek artmaktadır.

Karşılaşılan sorunların yaygınlığı nedeniyle önemli bir inceleme alanı olan 'bina kabuğunun bütünleșik nemsel-ısıl davranıșı'nı değerlendirmeye yönelik yazılımların ele alındığı bu yazıda, kullanılacak yazılımı belirlerken ve yazılımı kullanırken dikkat edilmesi gereken önemli konular üzerinde durulmuş ve bunlara yönelik akış diyagramları oluşturulmuştur. Konunun anlaşılırlığını artırmak amacıyla bir tip duvar tasarım çalışması açıklanarak yazılımların kullanım süreci örneklendirilmiştir.

Bina kabuğunun bütünleşik nemsel-1sıl performansına ilişkin doğru ve güvenilir bilgisayarlı benzetim sonuçlarının, bulunduğu ortam şartlarında uygun davranış gösteren bina kabuğu tasarımı ve uygulamasına girdi sağlayarak kullanıcı konforunun artmasına, sağlıklı ve sürdürülebilir bina için uygun 
yapısal çözümlerin geliştirilmesine katkı yapması beklenmektedir. Ayrıca, yapı ürünlerinin geliştirilmesine katkıda bulunacağı ve araştırmacılara kaynak oluşturacağı da düşünülmektedir. Bu açıdan, bilgisayarlı benzetim uygulamaları içeren çalışmaların deney ve ölçmelerle de desteklenerek geliştirilmesi ve yaygınlaştırılması önemli görülmektedir.

Bilgi notu: Uygulama örneği için TÜBİTAK 107M532 numaralı "Pomza Taşı Agregalı Beton Bloklarla Yapılan Dış Duvarların Isıl ve Nemsel Performansı, Yaşam Dönemi Enerji ve Ekonomik Etkinliğì" isimli araştırma projesinden yararlanılmıştır.

\section{KAYNAKLAR (REFERENCES)}

1. ISO, ISO $\mathbf{1 5 6 8 6}$ - Buildings and constructed assets - Service life planning - Part 1: General principles and framework, ISO, İsviçre, 2011.

2. UI-EOLBNL, Getting started with EnergyPlus - Basic concepts manual, University of Illinois \& Ernest Orlando Lawrence Berkeley National Laboratory, A.B.D., 2011.

3. IBP, Software/WUFI/Downloads - WUFI 2D online help, Fraunhofer - Institut für Bauphysik, 2011. www.hoki.ibp.fhg.de, Erişim: 6.3.2012.

4. EOLBNL, COMIS multizone air flow model, Ernest Orlando Lawrence Berkeley National Laboratory, A.B.D., 2003. http://epb.lbl.gov/ comis/, Erişim: 8.1.2012.

5. Karagiozis, A., "Advanced numerical models for hygrothermal research", Moisture analysis and condensation control in building envelopes, ASTM Manual 40, Editör: Trechsel, H., ASTM, Philadelphia, A.B.D., 90-106, 2001.

6. Wolonszyn, M., Rode, C., 'Tools for performance simulation of heat, air and moisture conditions of whole buildings', Building Simulation, Cilt 1, No 1, 5-24, 2008.

7. Straube, J., Burnett, E., "Overview of hygrothermal (HAM) analysis methods", Moisture analysis and condensation control in building envelopes, ASTM Manual 40, Editör: Trechsel, H., ASTM, Philadelphia, A.B.D., 8189, 2001.

8. Ramos, N.M.M., Delgado, J.M.P.Q., Barreira, E., de Freitas, V.P., "Hygrothermal numerical simulation: Application in moisture damage prevention", Numerical simulations - examples and applications in computational fluid dynamics, Editör: Angermann, L., InTech, Rijeka, Hirvatistan 97-122, 2010. www.intechopen.com/articles/, Erişim: 3.2.2012.

9. Holm, A.H., Kuenzel, H.M., "Practical application of an uncertainty approach for hygrothermal building simulations - drying of an AAC flat roof', Building and Environment, Cilt 37, No 8-9, 883-889, 2002.

10. Delgado, J.M.P.Q., de Freitas, V.P., Ramos,
N.M.M., Barreira, E., "Numerical simulation of exterior condensations on façades: The undercooling phenomenon", Thermal performance of the exterior envelopes of whole buildings XI int. conference, Florida, Aralık 2010. www.ornl.gov/sci/buildings/2010/B11\%20 papers/43 Delgado.pdf, Erişim: 3.2.2012.

11. BLOCON, 1D-HAM, BLOCON, İsveç. www.buildingphysics.com/index-filer/Page1762. htm, Erişim: 6.3.2012.

12. Hagentoft, C.E., Blomberg, T., 1D-HAM coupled heat, air and moisture transport in multi-layered wall structures - Manual with brief theory and an example, Lund-Gothenburg Group for Computational Building Physics, İsveç, 2000. www.buildingphysics.com/manuals/ 1dham.pdf, Erişim: 6.3.2012.

13. Nicolai, A., Grunewald, J., Delphin 5 - User manual and program reference. http:// bauklimatik-dresden.de/downloads.php, Erişim: 6.3.2012.

14. Cornick, S., Maref, W., Abdulghani, K., van Reenen, D., 1-D hygIRD: A simulation tool for modeling heat, air and moisture movement in exterior walls, National Research Council, Kanada, NRCC-46896, 2003. www.nrc-cnrc.gc. ca/obj/irc/doc/pubs/nrcc46896/nrcc46896.pdf, Erişim: 6.3.2012.

15. Karagiozis, A., Salonvaara, M., "Appendix I LATENITE", Moisture analysis and condensation control in building envelopes, ASTM Manual 40, Editör: Trechsel, H., ASTM, Philadelphia, A.B.D., 179-181, 2001.

16. Physibel, GLASTA - Diffusion - Condensation - Drying - Extended Glaser Method, Physibel, Belçika. $\quad$ http://www.physibel.be/v0n2gl.htm, Erişim: 6.3.2012.

17. dos Santos, G.H., Mendes, N., "Analysis of numerical methods and simulation time step effects on the prediction of building thermal performance", Applied Thermal Engineering, Cilt 24, No 8-9, 1129-1142, 2004.

18. Trechsel, H.R. "Moisture Primer", Moisture analysis and condensation control in building envelopes, ASTM Manual 40, Editör: Trechsel, H., ASTM, Philadelphia, A.B.D., 1-15, 2001.

19. Kus, H., Edis, E., Göcer, Ö., Özkan, E., "Performance assessment of pumice aggregate concrete block walls", $\mathbf{8}^{\text {th }}$ Int. Masonry Conference, Dresden, 1037-1046, 4-7 Temmuz 2010.

20. Edis, E., Kus, H., Göçer, Ö., "Pumice aggregate concrete block wall assembly design by hygrothermal performance simulation", ICBEST 2010, Vancouver, 161-168, 27-30 Haziran 2010.

21. TSE, Binalarda ısı yalıtım kuralları, Türk Standartları Enstitüsü, Ankara, 1998.

22. Briggen, P.M., Blocken, B., Schellen, H.L., "Wind-driven rain on the facade of monumental tower: Numerical simulation, full-scale validation 
and sensitivity analysis", Building and Environment, Cilt 44, No 8, 1675-1690, 2009.

23. Decareau, C.P.; Kan, L.; Pinon J.P., "Inputs and Analyses: An End User's Perspective of HeatAir-Moisture Data", Journal of ASTM Int., Cilt 4, No 8, 1-8, 2007.

24. Abuku, M., Jannsen, H., Roels, S., "Impact of wind-driven rain on historic brick wall buildings in a moderately cold and humid climate: Numerical analyses of mould growth risk, indoor climate and energy consumption", Energy and Buildings, Cilt 41, No 1, 101-110, 2009.

25. Koci, V., Madera, J. Cerny, Robert, C., "Exterior thermal insulation systems for AAC building envelopes: Computational analysis aimed at increasing service life", Energy and Buildings, Cilt 47, No 1, 84-90, 2012.

26. Torres, M.I.M, de Freitas, V.P, "Treatment of rising damp in historical buildings: wall base ventilation", Building and Environment, Cilt 42, No 1, 424-435, 2007.
27. Steeman, H.J., van Belleghem, M., Janssens, A., de Paepe, M., "Coupled simulation of heat and moisture transport in air and porous materials for the assessment of moisture related damage", Building and Environment, Cilt 44, No 10, 2176-2184, 2009.

28. Kalamees, T., Vinha, J., "Hygrothermal calculations and laboratory tests on timberframed wall structures", Building and Environment, Cilt 38, No 5, 689-697, 2003.

29. Defraeye, T., Blocken, B., Carmeliet, J., "Influence on uncertainty in heat-moisture transport properties of convective drying of porous materials by numerical modelling", Chemical Engineering Research and Design, Cilt 91, No 1, 36-42, 2013.

30. Blocken, B., Carmeliet, J., "On the errors associated with the use of hourly data in winddriven rain calculations on building facades", Atmospheric Environment, Cilt 41, No 11, 2335-2343, 2007. 